\title{
"PRAGUE" randomized clinical trials: pride of Czech cardiology
}

\author{
Petr Widimský, Harry Suryapranata* \\ Cardiocenter, 3rd Faculty of Medicine, Charles University, Prague, Czech Republic, *Department of Cardiology, Zwolle, The Netherlands
}

Address: prof. MUDr. Petr Widimský, DrSc., FESC, Department of Cardiology, 3rd Faculty of Medicine and Kralovske Vinohrady University Hospital, Šrobárova 50, 10034 Prague 10, Czech Republic, e-mail: Widim@fnkv.cz

\section{Background}

The Czech Society of Cardiology was founded in 1929 and is the third oldest cardiology society in the world. In 2009, we celebrate the 80th anniversary of the founding of our society. To mark this occasion, I was invited by Michael Aschermann - Editor-in-Chief of Cor et Vasa - to contribute by a special article reviewing all randomized clinical trials with the acronym "PRAGUE". I accepted with pleasure and invited Harry Suryapranata to join me. Harry Suryapranata was my PCI teacher and my research inspiration in my early steps in the field of interventional cardiology. Dr. Suryapranata was also one of the co-authors of the first PRAGUE trial manuscript. In 2007, he was awarded (on behalf of the Zwolle group) - for his overall contribution to the development of primary PCI - the "Andreas Gruntzig Lecture and Award" during the annual congress of the European Society of Cardiology (Figure 1). In fact, our trials (first Zwolle and first Prague) shared quite a lot of similarities, i.e.:

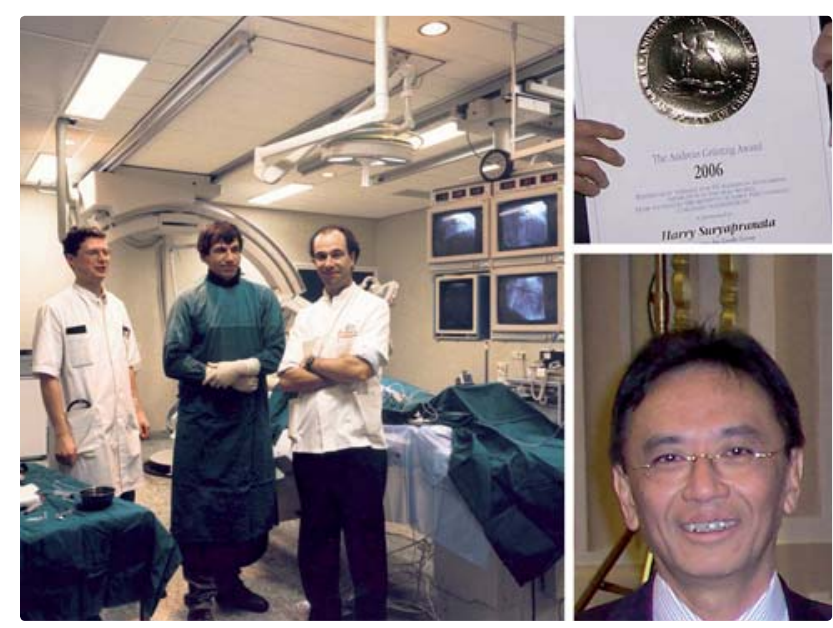

Figure 1 The original (1993) Zwolle group of interventional cardiologists - pioneers of primary PCI. From left to right: Felix Zijlstra, Jan Hoorntje, Menko-Jan DeBoer, Harry Suryapranata
1. Geography: the size of our network area served by medical emergency service

2. The number of population in our catchment area (1.5 million in the Zwolle area)

3. The number of referral hospitals (17 in the Zwolle area)

4. Reduction in total time delay by fast tract facilities: 215 to $178 \mathrm{~min}$

Below, the past, present and future randomized clinical trials from the "PRAGUE Study Group workshop" are presented in an overview (Table 1). Also the VINO trial (conducted within the same network and not named by a "PRAGUE" acronym just because we did not expect more trials in this series at the beginning) is included.

Before describing individual trials, we would like to look back at how all this happened. During my (P.W.) PCI training in Zwolle (NL) between 1992 and 1994, I was fascinated by the large benefit seen in STEMI patients treated by primary PCI. The Zwolle group (Figure 1) was pioneering primary PCI for STEMI in those years. After returning to my hospital at Královské Vinohrady (a quarter of Prague), we decided with my colleagues to stop completely thrombolytic treatment in our Cardiocenter and since October 5, 1995 all STEMI patients were treated by primary PCI. The STEMI in-hospital mortality fell dramatically from $11 \%$ (1994) to $4 \%$ (1996). Thus, we started to think about the ways how to offer such benefit also to patients living outside Prague, who present with their STEMI to a local non-PCI hospital. The design of the first PRAGUE study was prepared. It was called simply "PRAGUE" (not PRAGUE-1), because we did not expect additional studies to follow. The acronym "PRAGUE" means in full text „PRimary Angioplasty for patients from General non-PCI hospitals transferred to PCI Units with or without Emergency thrombolysis".

The PRAGUE study protocol was prepared and application for a research grant was submitted to the Czech 
Table 1 Overview of the PRAGUE randomized clinical trials

\begin{tabular}{|c|c|c|c|c|}
\hline Acronym & Principal Investigator(s) & Years of enrollment & Topic & $\begin{array}{l}\text { Hot Line / Late Breaking } \\
\text { Clinical Trials session } \\
\text { presentation at major } \\
\text { congresses }\end{array}$ \\
\hline PRAGUE & P. Widimský & 1997-1999 & $\begin{array}{l}\text { Three reperfusion strategies for STEMI patients } \\
\text { admitted to non- } \mathrm{PCI} \text { hospital }\end{array}$ & ESC 1999 \\
\hline VINO & R. Špaček, P. Widimský & 1998-2001 & $\begin{array}{l}\text { Emergent CABG vs. early conservative treatment } \\
\text { of non-STEMI }\end{array}$ & $\begin{array}{l}\text { ESC } 2001 \\
\text { TCT } 2002\end{array}$ \\
\hline PRAGUE-2 & P. Widimský & 1999-2002 & $\begin{array}{l}\text { Immediate thrombolysis vs. inter-hospital } \\
\text { transfer for primary PCI }\end{array}$ & $\begin{array}{l}\text { ESC } 2002 \\
\text { TCT } 2002 \\
\text { ESC + WCC } 2006 \text { (5-year } \\
\text { follow-up) }\end{array}$ \\
\hline PRAGUE-3 & J. Kettner & 2000-2001 & $\mathrm{PCl}$ in Q-MI after $>24$ hours from symptom onset & None \\
\hline PRAGUE-4 & P. Widimský, Z. Straka & 2000-2002 & $\begin{array}{l}\text { On-pump vs. off-pump CABG in unselected } \\
\text { patients }\end{array}$ & $\begin{array}{l}\text { ESC } 2002 \text { (surgical results) } \\
\text { ACC } 2004 \text { (CAG follow-up) }\end{array}$ \\
\hline PRAGUE-5 & R. Jirmár̆ & $2002-2006$ & $\begin{array}{l}\text { Very early }(24 \mathrm{~h}) \text { discharge after STEMI } \\
\text { treated by primary } \mathrm{PCl}\end{array}$ & None \\
\hline PRAGUE-6 & Z. Straka, P. Widimský & $2006-$ & On-pump vs. off-pump CABG in high risk patients & \\
\hline PRAGUE-7 & P. Toušek, P. Widimský & 2007-2009 & $\begin{array}{l}\text { Early upfront abciximab vs. bailout } \\
\text { abciximab in cardiogenic shock }\end{array}$ & ESC 2009 \\
\hline PRAGUE-8 & Z. Mot'ovská, P. Widimský & 2006-2007 & $\begin{array}{l}\text { Clopidogrel pretreatment vs. no pretreatment } \\
\text { before elective CABG }\end{array}$ & ESC 2007 \\
\hline PRAGUE-9 & $\begin{array}{l}\text { V. Kočka, P. Widimský, } \\
\text { Z. Straka }\end{array}$ & 2007- & $\begin{array}{l}\text { Combined surgery (CABG + MIVP) vs. } \mathrm{PCl} \text { alone } \\
\text { for patients with ischemic mitral regurgitation }\end{array}$ & None \\
\hline PRAGUE-10 & P. Oštádal & 2007- & Trimetazidine in acute heart failure & \\
\hline PRAGUE-11 & F. Bednář & 2006-2007 & Platelets and off-pump surgery & None \\
\hline PRAGUE-12 & Z. Straka, P. Widimský & 2007- & $\begin{array}{l}\text { MAZE vs. no MAZE in unselected cardiac } \\
\text { surgery candidates with atrial fibrillation }\end{array}$ & \\
\hline PRAGUE-13 & L. Groch, O. Hlinomaz & $2008-$ & $\begin{array}{l}\text { Multivessel } \mathrm{PCl} \text { vs. } \mathrm{PCl} \text { of infarct artery only } \\
\text { in STEMI patients with multivessel disease }\end{array}$ & \\
\hline
\end{tabular}

Ministry of Health - Internal Grant Agency. The result of this application came as a bad surprise for us: I was invited to attend the meeting of the Scientific Board of the Ministry and to explain how it was possible that we were planning a research project extremely dangerous for patients who were most likely to die during inter-hospital transfers from non-PCI hospitals to PCI centers. The board agreed that such a dangerous and unethical project should not be supported by a grant. This ministerial scientific board went even further and proposed that we should not be allowed to run the project (even without the grant support). Fortunately, before writing such a prohibitive decision they consulted the Board of the Czech Society of Cardiology for its view. The Czech Society of Cardiology Board met and after a long discussion (based on the evidence available by 1996) decided by 12:1 votes to support the PRAGUE Study project (Figures 2-4). Thus, the final decision of the Health Ministry was to refuse financial support, but to allow us to run the trial if we wished so without a research grant. A small group called "Prague Study Group" (P. Widimský, L. Groch, M. Želízko, M. Aschermann, T. Buděšínský) agreed to run the project even without financial support. The protocol compared three standard treatment options, which were routinely reimbursed to the hospitals by insurance companies and thus no money was necessary for a simple design trial to start. The local ethics committees of all 21 participating hospitals approved the study protocol. Data collection and analysis were done by physicians from the 21 participating hospitals enthusiastically based on a simple case report form.

The following part briefly describes the completed and the ongoing PRAGUE trials.

\section{PRAGUE-1 trial}

This trial was described at the introduction and is widely known, thus we provide here just the reference to the main manuscript and a picture (Figure 5) of one of our first successful primary PCI patients on top of Kala Pattar (5465 m above sea level) with Mount Everest seen in the back.

\section{VINO trial}

Shortly after the beginning of the PRAGUE-1 study, we started preparations of the protocol for a smaller study testing the role of emergent coronary angiography $( \pm$ PCI) in non-ST segment elevation acute myocardial infarction within 24 hours after admission. The results of this small 


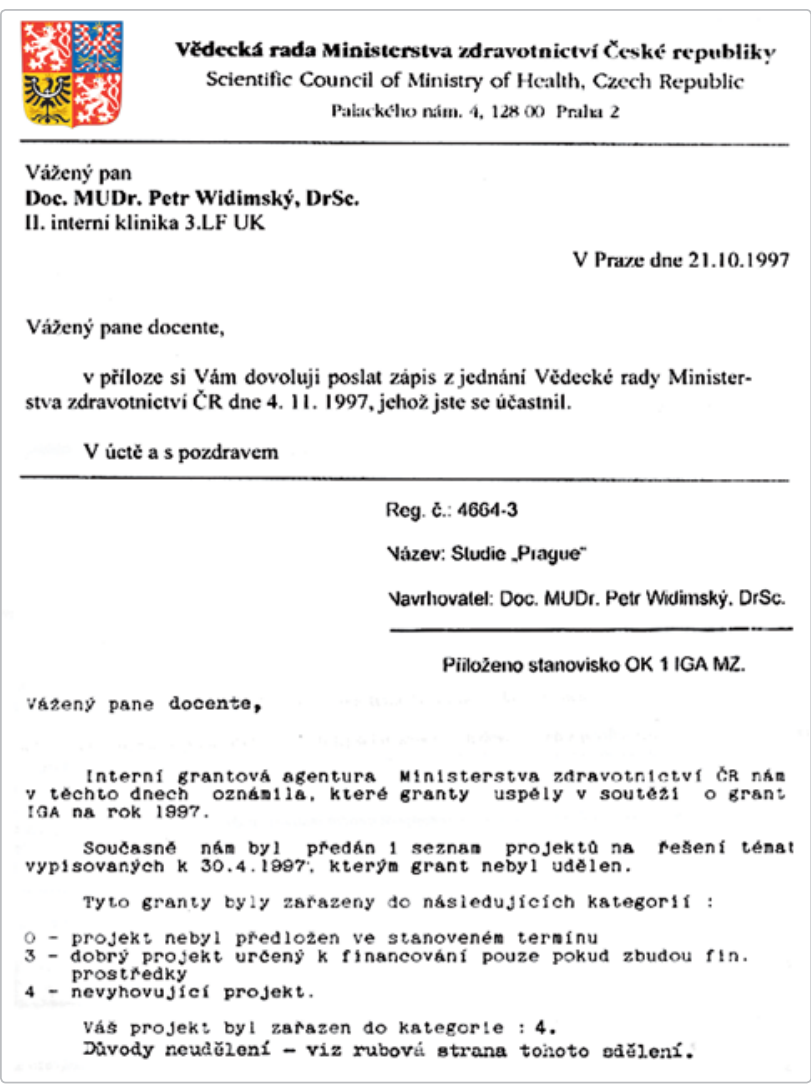

Figure 2 Decision letter from the Czech Ministry of Health (1997) with the statement that the grant application "PRAGUE Study" was classified as " 4 " - i.e. unsatisfactory

study surprised us - the very urgent invasive strategy decreased mortality (compared to a very conservative strategy) far more than among STEMI patients!

Špaček $R$, Widimský $P$, Straka Z, Jirešová E, Dvořák J, Polášek $R$, et al. Value of first day angiography/angioplasty in evolving non-ST segment elevation myocardial infarction: An open multicenter randomized trial: The VINO study. Eur Heart J 2002;23(3):230-8.

\section{PRAGUE-2 trial}

After the end of the PRAGUE-1 study in 1999, all authors considered the answer to be very clear: primary PCI should be the treatment of choice for all STEMI patients, even when they need inter-hospital transport. However, the

\section{Zảpis ze schüze výboru CKS konané dne 20.11. 1997 v Praze}

Pritomni prof Čerbảk, doc. Stančk, doc Chaloupka, doc. Widimskỷ, dr. Bytešnik. doc Hradec, dr. Málek, doc. Niederle, dr. Rozsival, dr Škovrảnek, doc. Toman. doc Vojàcek, dr. Żelizko

X. Rüzné

a) Studie Prague

Doc Widimsky pożadal členy vỷbon o stanovisko $k$ teto studii a $k$ rozhodnuti odborne komise OK OI IGA ML CR tento grantový projekt nedoporučit $k$ prijeti Clenové vyboru doc Widimského podporili ve sporné pasà̃s, że transport pacienta je akceptovatelny do vzdalenosti max. 60 minut $\mathrm{k}$ primarni PTCA bez zahajeni trombolytick leiby

Figure 4 Minutes from the meeting of the Board of the Czech Society of Cardiology (1997) showing the support of the Board for the project

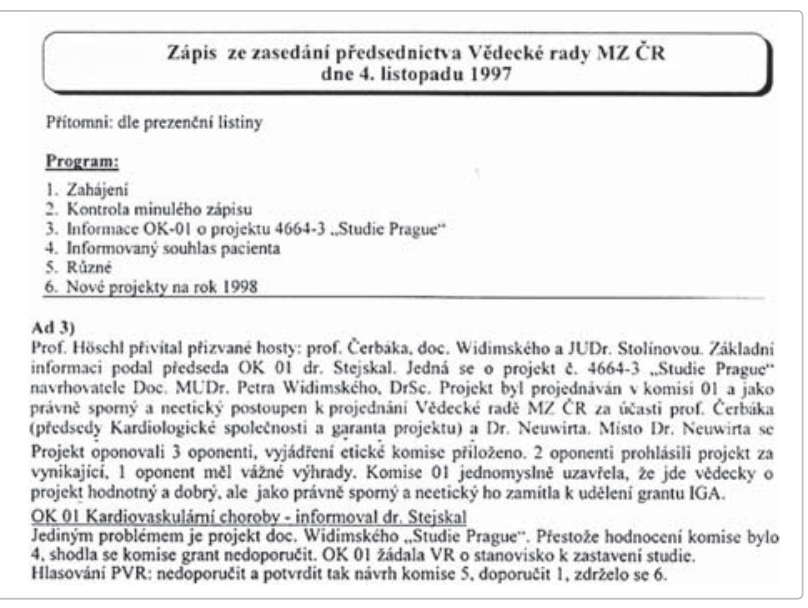

Figure 3 Detailed minutes from the meeting of the Scientific Board of the Czech Ministry of Health (1997) with statements about the "PRAGUE Study" grant application: the project was labeled as legally questionable and non-ethical (despite the fact that two reviewers considered the project excellent, while one reviewer had serious reservations). The voting results: 5 members against the PRAGUE Study, 1 member in favor of the PRAGUE Study, 6 members abstained (remained neutral)

Czech health care authorities and, also, many "thrombolysis-lovers" among cardiologists criticized the study for its small size and refused to adopt the study results for daily practice. Thus, we decided to run a larger (truly nationwide) randomized study with the primary end-point being all-cause mortality. Fifty-one Czech hospitals (approx. half of the country) agreed to participate. This PRAGUE-2 study enrolled 850 patients and was terminated prematurely for two reasons: (1) marked benefit (2.5-fold decrease in mortality) from the primary PCI strategy among patients randomized $>3$ hours after symptom onset and, (2) the growing resistance of the non-PCI hospitals to randomize patients to the thrombolytic arm. The fact that the preliminary study results (before they were even analyzed and published!) convinced the non-PCI hospitals to transfer all their STEMI patients routinely for primary PCI, was the most important trigger of the fast development after the

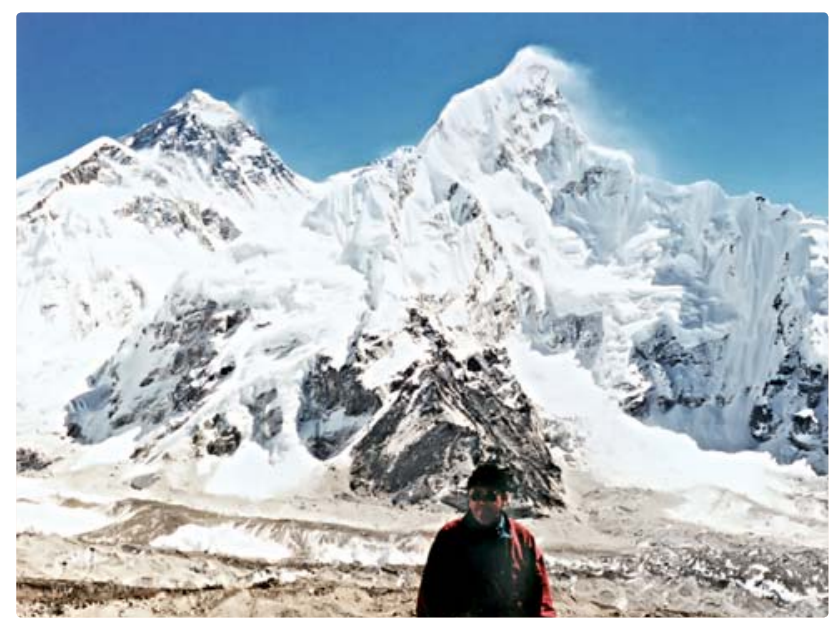

Figure 5 One of the first Czech primary $\mathrm{PCl}$ patients 9 months later climbed on the top of Kala Pattar in Nepal. Mount Everest is seen on the left, behind 
end of the PRAGUE-2 study: thrombolysis was almost completely abandoned in the whole country within the first year after PRAGUE-2. In those few counties (regions) still not having PCI facilities new catheterization labs were opened and interventional cardiologists from experienced centers were invited to start the primary PCI service. In 2004, the whole country was covered by primary PCI services with only one exception - the last region (Vysočina) opened its PCI center later (2007).

Widimský P, Buděšinský T, Voráč D, Groch L, Želízko M, Aschermann $M$, et al. Long distance transport for primary angioplasty vs. immediate thrombolysis in acute myocardial infarction: Final results of the randomized national multicentre trial-PRAGUE-2. Eur Heart J 2003;24(1):94-104.

Widimský P, Bílková D, Pěnička $M$, Novák $M$, Laníková $M$, Poŕizka $V$, et al. Long-term outcomes of patients with acute myocardial infarction presenting to hospitals without catheterization laboratory and randomized to immediate thrombolysis or interhospital transport for primary percutaneous coronary intervention. Five years' follow-up of the PRAGUE-2 trial. Eur Heart J 2007;28(6):679-84.

\section{PRAGUE-3 trial}

The PRAGUE-3 trial was designed to test whether patients presenting with STEMI or Q-MI > 24 hours after symptom onset should undergo immediate coronary angiography \pm PCI or should be rather treated conservatively. The design was thus similar to an international OAT trial, performed several years later. Unfortunately, the PRAGUE-3 trial was stopped prematurely due to its very low patient recruitment rate (only 44 patients enrolled during 1.5 years in 4 participating centers). There was no difference between the two treatment groups and the results were never published.

\section{PRAGUE-4 trial}

The PRAGUE-4 trial analyzed whether off-pump surgery is superior to on-pump surgery in unselected patients undergoing $\mathrm{CABG}$. The surgical results were slightly positive for off-pump procedures, while one-year angiographic controls for bypass graft patency were slightly favoring on-pump surgery.

Widimský P, Straka Z, Štros P, Jirásek K, Dvořák J, Votava $J$, et al. One-year coronary bypass graft patency: A randomized comparison between off-pump and on-pump surgery angiographic results of the PRAGUE-4 trial. Circulation 2004;110(22):3418-23.

Straka Z, Widimský P, Jirásek K, Štros P, Votava J, Vaněk $T$, et al. Off-pump versus on-pump coronary surgery: Final results from a prospective randomized study prague-4. Ann Thoracic Surg 2004;77(3):789-93.

\section{PRAGUE-5 trial}

This small trial randomized patients with single-vessel coronary artery disease after successful primary PCI into a very early discharge group and a standard discharge group. Results showed feasibility of very early (after 29 hours) discharge in a highly selected low-risk STEMI population.

Jirmář R, Widimský P, Čapek J, Hlinomaz O, Groch L. Next day discharge after successful primary angioplasty for acute ST elevation myocardial infarction. An open randomized study „PRAGUE-5“. Int Heart J 2008;49(6):653-9.

\section{PRAGUE-6 trial}

The trial is still ongoing, with the end of enrollment expected in late 2009 or early 2010. Patients with EuroSCORE $\geq 6$ scheduled for bypass surgery are randomized between off-pump versus on-pump surgery.

\section{PRAGUE-7 trial}

Patients with cardiogenic shock were randomized between routine early (upfront, before coronary angiography) abciximab and selective abciximab (given only to some patients based on CAG finding, i.e. during PCI). This trial was presented during the Hot Line session at the ESC Congress 2009 in Barcelona. The manuscript is currently undergoing peer review.

\section{PRAGUE-8 trial}

The ESC guidelines for PCI published in 2005 recommended to pre-treat all patients undergoing elective coronary angiography for chronic stable coronary artery disease by clopidogrel 300-600 mg. We did not believe in this strategy and thus we decided to design a randomized trial comparing this guidelines-recommended strategy with our routinely used strategy (no clopidogrel before angiography, clopidogrel at loading dose given only before PCI, i.e., based on the angiographic finding). The trial confirmed that our strategy is at least equal (or even slightly better) than the guideline-recommended approach.

Widimský P, Motovská Z, Šimek S, Kala P, Pudil R, Holm F, Petr R, Bílková D, Skalická H, Kuchynka P, Poloczek M, Miklík R, Malý M, Aschermann M, PRAGUE-8 Trial Investigators. Clopidogrel pre-treatment in stable angina: for all patients $>6 \mathrm{~h}$ before elective coronary angiography or only for angiographically selected patients a few minutes before PCI? A randomized multicentre trial PRAGUE-8. Eur Heart J 2008;29(12):1495-503.

\section{PRAGUE-9 trial}

The most ambitious, but also the most difficult of the new generation (after PRAGUE-5) of our trials. Patients with coronary artery disease indicated for revascularization and having also ischemic or degenerative mitral regurgitation were randomized to either complete surgical treatment (bypass grafting + mitral valvuloplasty) or multivessel PCI alone (leaving mitral regurgitation for conservative treatment). Although 8 Czech tertiary cardiac centers 
agreed to participate, the only center enrolling patients was our center (other centers contributed only 1-3 randomized patients during a period $>2$ years). Even we (as authors of this trial design and thus most enthusiastic of all investigators) faced difficulties in enrolling patients. Most patients after reading the informed consent form refused randomization and expressed their clear preference for either surgery or PCI. Thus, we had to stop this trial for a low enrollment rate (similar to PRAGUE-3).

\section{PRAGUE-10 trial}

This trial was designed solely by Petr Oštádal when he joined our team in 2006. He moved to other hospital 2 years later and he continued to run the trial (testing trimetazidine in acute heart failure patients) from there.

\section{PRAGUE-11 trial}

A small but interesting trial performed in our cardiac surgery department.

Bednář F, Osmančík P, Vaněk T, Mociková H, Jareš M, Straka Z, Widimský P. Platelet activity and aspirin efficacy after off-pump compared with on-pump coronary artery bypass surgery: results from the prospective randomized trial PRAGUE 11-Coronary Artery Bypass and REactivity of
Thrombocytes (CABARET). J Thorac Cardiovasc Surg 2008; 136(4):1054-60.

\section{PRAGUE-12 trial}

This trial is still ongoing, with the end of enrollment expected in late 2009 or early 2010. Patients with atrial fibrillation and any other disease (coronary, valvular, congenital), scheduled for cardiac surgery, are randomized to major surgery (bypass, valve, etc.) + MAZE procedure or major surgery alone (without the MAZE procedure).

\section{PRAGUE-13 trial}

This trial is led by L. Groch and O. Hlinomaz from St. Anne Hospital in Brno and started enrollment in 2009. Patients with STEMI and multivessel disease are randomized to infarct-vessel treatment alone versus multi-vessel PCI.

The impact of the PRAGUE trials on Czech cardiology was important for many reasons: (a) decrease in STEMI mortality, (b) overall improvement of patient care, (c) formation of regional networks of Emergency Medical Services \& PCI centers \& non PCI hospitals, (d) offer a basis for multicenter research cooperation (previously not seen in the Czech Republic). 